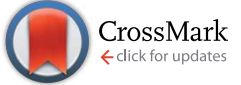

Cite this: RSC Adv., 2017, 7, 7679
Received 15th November 2016 Accepted 17th January 2017

DOI: $10.1039 / c 6 r a 26848 j$

www.rsc.org/advances

\section{The formation of haloacetamides, as an emerging class of N-DBPs, from chlor(am)ination of algal organic matter extracted from Microcystis aeruginosa, Scenedesmus quadricauda and Nitzschia palea†}

\begin{abstract}
Ni Zhang, ${ }^{a}$ Cao Liu, ${ }^{b}$ Fei Qi ${ }^{\star a}$ and Bingbing Xu*c
Critical algal blooms in lakes increased the concentration of algal organic matter (AOM), significantly altering the drinking water treatment requirements, including coagulation, oxidation and disinfection. This study utilized Microcystis aeruginosa (cyanobacteria), Scenedesmus quadricauda (Chlorella) and Nitzschia palea (diatom) as models to investigate the AOM's primary characteristics and their contribution to the formation of chloroacetamides as novel disinfection byproducts (DBPs). Spectral analysis was used to characterize the proteins, carbohydrates and amino acids in AOM. The generation of chloroacetamides during chlor(am)ination was determined by gas chromatography with electron capture detection. Although Microcystis aeruginosa is the dominant species in freshwater worldwide, the AOM of Nitzschia palea showed the highest dissovled organic carbon (DOC) formation (4.02 or $1.42 \mathrm{ng}$ per cell in extracellular organic matter (EOM) or intracellular organic matter (IOM), respectively). Scenedesmus quadricauda, as a typical green algae, showed the greatest formation potential of chloroacetamides in chlor(am)ination. Monochloroacetamide was the dominant chloroacetamide, which has not previously been reported and differed from the results reported for other precursors. In summary, AOM should be considered an important precursor for the formation of chloroacetamides.
\end{abstract}

\section{Introduction}

In recent years, many lakes and reservoirs have undergone eutrophication, resulting in seasonal algal blooms. This situation has been exacerbated by global climate change and increased influx of pollutants into aquatic systems and their concentration. Algal blooms in lakes have become a serious problem threatening the safety of drinking water, as indicated by the Taihu Lake pollution incident in China at the end of May 2007. ${ }^{1}$ This problem became more serious under significant global climate change. Algal cells often release intracellular toxins and odor compounds that severely threaten the quality of the water supply, as the bloom lake was used as the water source. In addition, algal cells and their associated algal organic matter (AOM) cannot be removed efficiently by the conventional

${ }^{a}$ Beijing Key Lab for Source Control Technology of Water Pollution, College of Environmental Science and Engineering, Beijing Forestry University, Beijing 100083, PR China. E-mail: qifei@bjfu.edu.cn; Fax: +8610 62336596; Tel: +861062336615

${ }^{b}$ Beijing Water Science Technology Institute, Beijing, 100048, P. R. China

${ }^{\prime}$ State Key Laboratory of Environmental Criteria and Risk Assessment, Chinese Research Academy of Environmental Sciences, Beijing 100012, PR China. E-mail: xbb_hit@126.com

$\dagger$ Electronic supplementary information (ESI) available. See DOI: $10.1039 / \mathrm{c} 6 \mathrm{ra} 26848 \mathrm{j}$ drinking water treatment, but significantly increase the coagulant dosage and block filters, resulting in increased levels of disinfection by-products (DBPs) that was focused more in recent years as DBPs showing higher toxicity. ${ }^{2}$ Carbonaceous DBPs derived from algae have been studied in detail using cyanobacteria $^{3}$ and Chlorella ${ }^{4}$ as probes. The extracellular organic matter (EOM) released from the algal cells and intracellular organic matter (IOM) from cell autolysis have also been used as precursors to test the potential for DBPs formation and the contribution of EOM/IOM. ${ }^{5}$ Because of their high toxicity, nitrogenous DBPs from AOM have been evaluated in many recent studies, including studies of precursor identification, formation trends and disinfection mechanisms. ${ }^{6}$ Among all considering nitrogenous DBPs including haloacetonitrile, halogenated nitromethane and nitrosamines, haloacetamides (HAcAms) are a relatively newly identified group that have been reported in drinking waters. ${ }^{7}$ Five HAcAms, monochloroacetamide (MCAcAm), dichloroacetamide (DCAcAm), trichloroacetamide (TCAcAm), bromoacetamide (BAcAm) and dibromoacetamide (DBAcAm), were first quantified as DBPs in a 2000-2002 drinking water survey in the United States. ${ }^{\mathbf{3}}$ Importantly, HAcAms exhibited higher in vitro toxicity than traditional DBPs such as halomethanes, as well as other nitrogenous DBPs, ${ }^{9}$ leading to their receiving greater attention 
than other nitrogenous DBPs. However, research in this field has been limited to use of Microcystis aeruginosa or its derived $\mathrm{AOM}$ as the probe ${ }^{3}$ and natural organic matters in surface water or filtered drinking water. Indeed, there have been few investigations of the contribution of other species of algae to the potential formation of HAcAms. Here, the objectives of this study are to investigate (1) the primary characterization of AOM generated from three typical species of algae in lakes of China, Microcystis aeruginosa (MA), Scenedesmus quadricauda (SQ) and Nitzschia palea (NP); and (2) the contribution of extracted AOMs to the potential formation of HAcAms in that the Cl-HAcAms was focused in this study as their higher toxicity and lower exposure of bromide ion in fresh water of China. ${ }^{9}$

\section{Materials and methods}

\subsection{Algae cultivation, AOM extraction and characterization}

Three species of cyanobacteria were used in this study, MA, SQ and NP. Organisms were purchased from the Institute of Hydrobiology of the Chinese Academy of Sciences (Wuhan, Hubei, China). The cells of MA and SQ were cultured in BG-11 medium $(\mathrm{pH}=8.6)$, while NP was cultured in D-1 medium $(\mathrm{pH}=8.00-8.15)$. The components of BG-11 and D-1 are shown in Tables $\mathrm{S} 1$ and $\mathrm{S} 2, \uparrow$ respectively. All samples were incubated in $4.0 \mathrm{~L}$ volumes under laboratory conditions for $10 \mathrm{~d}\left(28^{\circ} \mathrm{C} ; 12\right.$ $\mathrm{h} / 12 \mathrm{~h}$ dark/light cycle; luminance $=2200$ lux; one passage every $5 \mathrm{~d}$ ). Cultures were used for subsequent separation of AOM fractions and disinfection experiments after the cells reached the exponential growth phase. During culture, samples of cell suspensions were collected every $48 \mathrm{~h}$ and diluted serially, after which their densities were determined by an optical microscope using hemocytometers daily until the beginning of the decline phase.

Centrifugal-filtration was used to extract the EOM and IOM of the selected algal species. The AOM extraction method was as follows: (a) $10 \mathrm{~mL}$ of cell suspension was centrifuged at $5000 \mathrm{rpm}, 2400 \times g$, for $15 \mathrm{~min}$, and the supernatant was then filtered through a $0.45 \mu \mathrm{m}$ polyethersulfone membrane filter to obtain the EOM sample; ${ }^{10}$ (b) next, $10 \mathrm{~mL}$ of ultrapure water was added to the same volume of the residue remaining in the centrifuge tube after the EOM extraction to wash the surface of the cells twice, after which the residual cells were re-suspended in ultrapure water. The cells were subsequently subjected to three cycles of freeze-thawing $\left(-80{ }^{\circ} \mathrm{C}\right.$ in an ultra-low freezer, $35^{\circ} \mathrm{C}$ in a water bath) before being centrifuged at $10000 \mathrm{rpm}$, $9600 \times g$, for $15 \mathrm{~min}$. The supernatant was then filtered again through a $0.45 \mu \mathrm{m}$ polyethersulfone membrane filter to obtain the IOM sample. ${ }^{11}$ Based on the above extraction process, there was no culture medium in the samples of EOM or IOM; therefore, the organic content in the culture medium would not contribute to the formation of DBPs. The extracted samples were prepared up to 3 days in advance and stored in a refrigerator at $4{ }^{\circ} \mathrm{C}$ until use. Dissolved organic carbon (DOC) was measured using a $3100 \mathrm{TC} / \mathrm{TN}$ analyzer (Jena, Germany). The Bradford method, ${ }^{12}$ anthrone-sulfuric ${ }^{13}$ and ninhydrin assays ${ }^{14}$ were used to determine the concentrations of the total protein, total carbohydrates and total amino acids in the AOM, respectively. Bovine serum albumin (BSA), glucose and lysine were used for calibration of protein, carbohydrate and amino acids analysis, respectively, which was conducted at $595 \mathrm{~nm}$, $620 \mathrm{~nm}$ and $570 \mathrm{~nm}$ using an UV/Vis spectrophotometer (T6, Purkinje general, China).

\subsection{DBP formation potential tests and DBPs analytical method}

Chlorination or chloramination experiments were conducted at $\mathrm{pH}=7$ that was adjusted by phosphate butter solution. Chlorination experiments were conducted according to the method developed by Dotson et al. using free chlorine and chloramine. ${ }^{15}$ Solutions contained AOMs that were chlorinated or chloraminated in sealed $50 \mathrm{~mL}$ amber glass bottles at ambient temperature in the dark for a pre-determined time ( $24 \mathrm{~h}$ or $72 \mathrm{~h}$ ). The required dosages of disinfectants were calculated as previously reported. ${ }^{16}$ Ascorbic acid at a concentration of $40 \mathrm{mg} \mathrm{L^{-1 }}$ was used to quench residual chlorine and monochloramine before DBPs analysis. ${ }^{17}$ Following incubation and quenching under ambient temperature, samples were extracted with methyl tert butyl ether (MTBE) and analyzed immediately by gas chromatography (GC) with an electron capture detector (ECD) using a HP-5 column $(30 \mathrm{~m} \times 0.25 \mathrm{~mm}$, ID $\times 0.25 \mu \mathrm{m}, \mathrm{J} \& W$ Scientific, Folsom, CA, USA $){ }^{11}$ which was also shown to be feasible and used in many previous studies. ${ }^{\mathbf{1 8 , 1 9}}$ Although many studies have focused on DCACAm and BAcAm at relatively higher concentrations,,$^{\mathbf{2 0} 21}$ no studies have reported the reliability of the analytic method used in this study. The temperature programs for DBPs detection were modified as follows: the column temperature was held at $35{ }^{\circ} \mathrm{C}$ for $9 \mathrm{~min}$, ramped to $40{ }^{\circ} \mathrm{C}$ at $2{ }^{\circ} \mathrm{C}$ $\min ^{-1}$ without any holding, then ramped to $160{ }^{\circ} \mathrm{C}$ at $40{ }^{\circ} \mathrm{C}$ $\min ^{-1}$ and held for $4 \mathrm{~min}$. Pure $\mathrm{N}_{2}$ (purity $>99.999 \%$ ) was

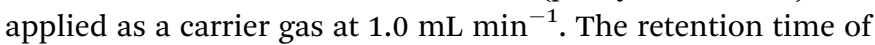
three kinds of DBPs and quality assurance (QA)/quality control (QC) results are shown in Table S3.†

\section{Results and discussion}

\subsection{Primary characterization of AOMs extracted from different algal species}

The characterization of AOM generated from MA, SQ and NP is shown in Fig. 1. Samples were obtained from the exponential growth phase of algae, in which dramatic increases in algal cell numbers were found for each species. The parameter of DOC/cell number was used to characterize AOMs extracted from different algal species, because of it being fair for each algae species. EOM showed a greater DOC concentration than IOM, independent of algal species. NP as another typical diatom species in China lakes as a dominant ${ }^{22}$ except MA, showed a significant organic matters releasing into EOM as $4.02 \times$ $10^{-6} \mathrm{mg}$ per cell, compared with MA and SQ. When compared with the results of other experiments, the value obtained in this study was much higher than that observed for diatoms such as Melosira sp. $\left(1.9 \times 10^{-8} \mathrm{mg}\right.$ per cell $)$ or Asterionella fronosu $\left(6.5 \times 10^{-7} \mathrm{mg}\right.$ per cell $),{ }^{23}$ even though the culture medium used was different. The regular Chlorella, SQ, showed the lowest 

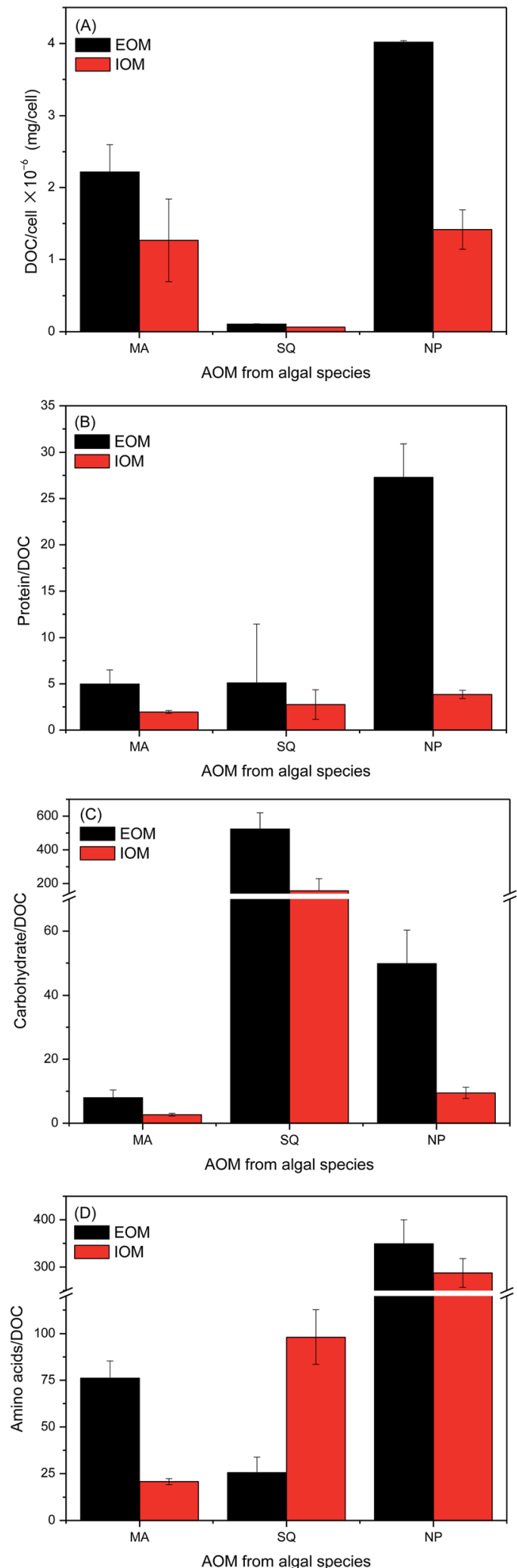

Fig. 1 DOC, protein, carbohydrate and amino acid in EOM/IOM of different algal species.

organic matter in both EOM and IOM $\left(2.21 \times 10^{-6} \mathrm{mg}\right.$ per cell and $1.28 \times 10^{-6} \mathrm{mg}$ per cell, respectively). ${ }^{23}$ Henderson et al. reported that the EOM extracted from Chlorella vulgairs was
$9.0 \times 10^{-9} \mathrm{mg}$ per cell in the exponential phase, ${ }^{23}$ while Yang et al. ${ }^{24}$ found this level to be $5.0 \times 10^{-7} \mathrm{mg}$ per cell. There was some difference from each other. The accumulation/release into IOM/EOM was much higher than Henderson or Yang reported values. Among blue-green algae, MA has been most thoroughly studied, and this organism is known to be responsible for organic matter accumulation in IOM and release into EOM. ${ }^{5}$ However, the release of organic matter into EOM from MA cells was less than that from NP. Here, the formation/ release of AOM from NP cells should be of concern because it has the potential to influence freshwater quality and the performance of drinking water treatment.

The levels of proteins (Fig. 1(B)), carbohydrates (Fig. 1(C)) and amino acids (Fig. 1(D)) were also investigated. To provide a fair comparison between different substances extracted from algal species, the following formula was used: [protein/ carbohydrate/amino acid]/[DOC]. The values for the above parameters were all much higher than 1.0. The polysaccharide dominated the components of carbohydrate would lead to the above result that were also observed as protein with larger molecular weight, which was not reported before. Moreover, polysaccharides were not hydrolyzed before analysis, which was reflected in the above results. The amino acid with numbers of carbon was higher than that of lysine as standards in this study, which would also lead to the above results. The protein and carbohydrate concentrations in EOM were higher than those in IOM, which was consistent with the DOC/cell, suggesting that proteins and carbohydrates might be easily released into the IOM. However, the same trend was not observed for amino acids. Among all investigated algal species, NP showed the highest accumulation/release of protein of $3.85 \mathrm{in} \mathrm{IOM/27.31} \mathrm{in}$ EOM. Melosira sp. or Asterionella fronosu produced a value of [protein/carbohydrate]/[DOC] close to 1.0, indicating that the carbohydrates generated from NP differed, ${ }^{23}$ which would be affected by the matrix and culture condition period. The exposure of protein in SQ and MA was very similar, although the former showed higher concentrations in both EOM and IOM. In a previous publication, the protein was only half of the total DOC, such as MA and Chlorella. ${ }^{25}$ The difference between the results in this study and those in a previous study might have been caused by variations in the algal culture conditions and the AOM extraction procedure. The accumulation/release of protein in AOM increased the formation potential of nitrogenous DBPs as the presence of nitrogen in protein. ${ }^{26}$ The potential formation of Cl-HAcAm from AOM of the investigated algal species is discussed later in this study. The carbohydrate accumulation/release in IOM/EOM might affect the formation of carbonaceous DBPs. Scenedesmus quadricauda showed the greatest carbohydrate accumulation/release in IOM (156.99)/ EOM (523.29), and these values were much higher than those observed for MA and NP. The carbohydrate concentration in AOM of MA was lowest, which was not expected, as MA is the dominant blue-green algae in many lakes and was focused most. ${ }^{27,28}$ The results shown in Fig. 1(C) suggested that SQ and NP algal species had a strong impact on carbonaceous DBPs formation. Although this aspect was not studied here, such a finding would be consistent with the results of a previous 
study. ${ }^{29}$ Much more consideration to AOM of SQ and NP should be given in DBPs formation field. NP species also showed the greatest yields of amino acids, with the concentration in EOM being higher than IOM. The same trend was also observed for MA. However, the amino acid accumulation in IOM of SQ was higher than its releasing into EOM, which was different from the results observed for MA and NP. Few studies have investigated amino acids in AOM generated from algal species, but their presence strongly influences nitrogenous DBPs formation. ${ }^{30}$ Based on the above primary characterization of AOM, NP has great potential to influence nitrogenous DBPs; if the DBPs extend to carbonaceous one, the AOM of SQ, should be considered.

\subsection{Formation potential of HAcAm DBPs from different algal species}

The potential for formation of three kinds of Cl-HAcAm including (chloroacetamide, dichloroacetamide and trichloroacetamide) during chlorination, is shown in Fig. 2. The fractions of AOMs and disinfection time influenced formation potential significantly as the first report on Cl-HAcAm formation from algae precursor as our acknowledgement from Web of Science, since haloacetamides were first reported as DBPs in a 2000-2002 drinking water survey. ${ }^{8}$ Interestingly, MCAcAm showed the highest yields in all fractions of AOM from different algal species. Previous studies have shown that the formation potential of MCAcAm is not great among haloacetamides generated from $\mathrm{NOMs}^{31}$ and surface water, ${ }^{7}$ and that DCAcAM or TCAcAm was the dominant species depending on the dose of disinfectant or reaction time. Although Chu et al. ${ }^{32}$ reported that MCAcAm exhibited more instability than DCAcAM/TCAcAm, the significantly high yield of MCAcAm observed here confirmed that MCAcAm was an important DBP generated from AOM. Other investigation also showed the presence of CAcAm in chlorination..$^{\mathbf{8} 33,34}$ Furthermore, AOMs extracted from SQ species showed the highest formation potential of all ClHAcAm. The EOM of SQ showed higher formation potential for Cl-HAcAm than IOM when the tested samples had the same DOC values, suggesting that the composition in EOM of SQ was favored to form Cl-HAcAm. SQ exhibited greater formation potential of Cl-HAcAm than MA, which was consistent with the results published for regular DBPs such as THMs and HAAs. ${ }^{24}$ Another interesting result of the present study was that IOM extracted from NP showed higher formation potential of ClHAcAm than EOM, which was not consistent with MA and SQ. Generally, less research has focused on the contribution of AOM of diatoms for DBPs formation, because diatoms are not the dominant species in shallow lakes. The regular carbonaceous DBPs formation from $C$. meneghiniana, a diatom species in
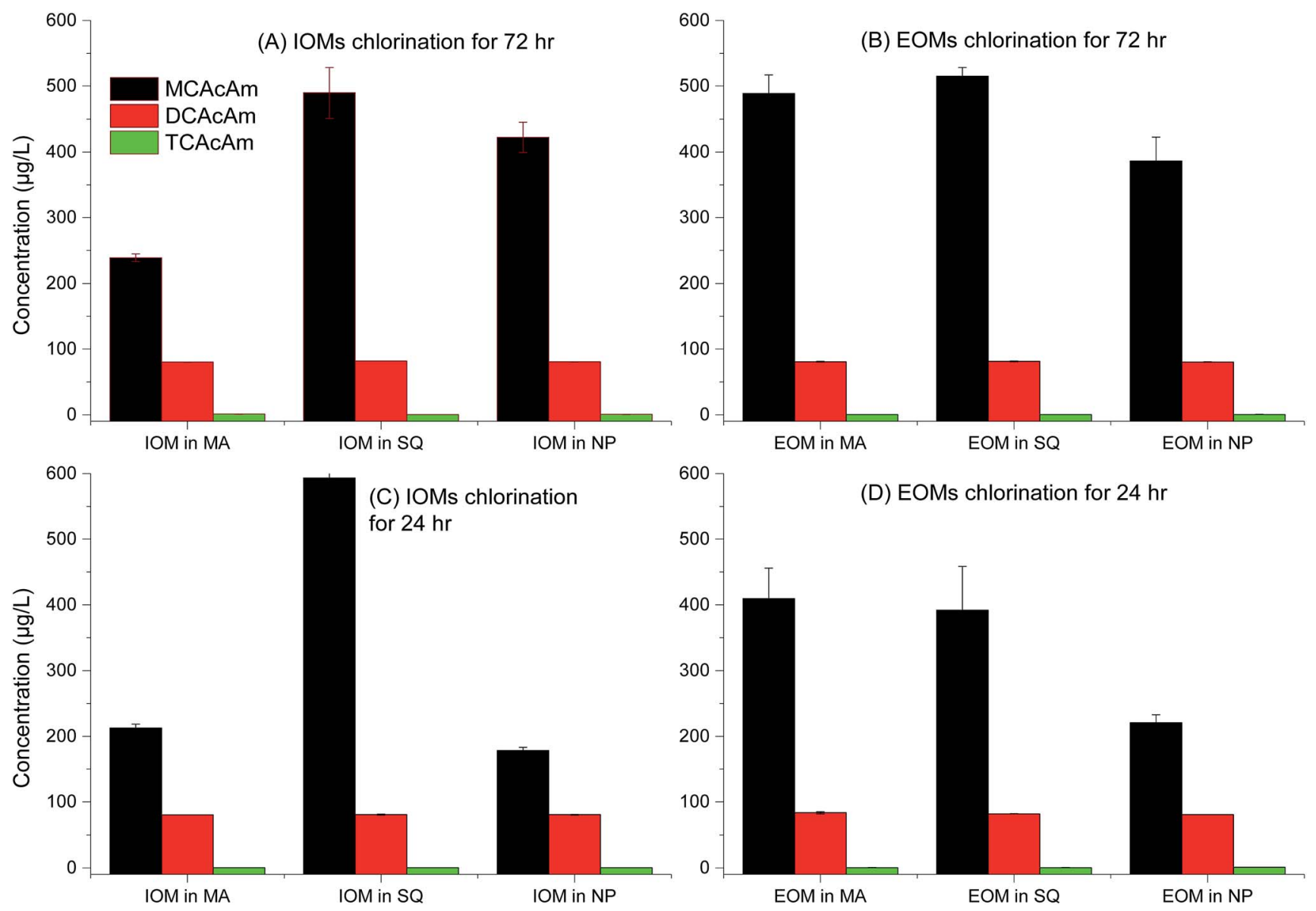

Fig. $2 \mathrm{Cl}$-HAcAm formation in chlorination AOMs extracted from different algae. 
Xiamen, China, was evaluated and their contribution to carbonaceous DBPs formation was found to be less than that of MA. ${ }^{35}$ Because the disinfection time decreased from $72 \mathrm{~h}$ to $24 \mathrm{~h}$, the concentration of Cl-HAcAm formed decreased greatly and MCAcAm was still the dominant DBP among all tested ClHAcAm. However, the concentration of Cl-HAcAm generated from IOM of SQ increased at some degree. A long disinfection time would degrade MCAcAm and lead to self-hydrolysis. ${ }^{32}$ Here, a long disinfection time led to higher concentrations of Cl-HAcAm formed from AOMs extracted from MA, and the EOM fraction of MA showed higher Cl-HAcAm formation potential. The formation potential of Cl-HAcAm from SQ species was more significant than that from MA. The concentration of Cl-HAcAm formed from EOM of SQ was higher than that from IOM after $72 \mathrm{~h}$ of disinfection. The contribution of NP AOMs for ClHAcAm formation potential was more important among all studied algal species; however, decreasing the disinfection time is a good method to decrease the form of Cl-HAcAm, which is more significant for the IOM fractions of NP.

When the disinfectant was switched to chloramine, the formation potential of Cl-HAcAm decreased relative to the chlorination. This decrease was more significant for MCAcAm than for DCAcAm and TCAcAm (Fig. 3). However, MCAcAm was still the dominant DBPs species. The formation potential of ClHAcAm in chloramation was still dependent on the algal species. AOMs extracted from SQ showed the highest yields of MCAcAm, while EOMs derived from MA and SQ showed higher formation potential than IOM, which was consistent with the chlorination. Nearly the similar variation in formation potential of Cl-HAcAm was observed between chloramination and chlorination, suggesting that the nitrogen in Cl-HAcAm originated from AOM, not chloramine. However, the lower oxidation ability of chloramine led to lower concentrations of formed ClHAcAm. Less difference in the formation potential of MCAcAm was observed between EOM and IOM of NP, which was different from that observed in chlorination. During chloramination, the short disinfection time increased the formation concentration of MCAcAm, which was different from chlorination. These results confirmed that disinfectant especially for free chlorine could degrade MCAcAm, which could also decay from hydrolysis. In summary, use of chloramine is an option to decrease the formation concentration of Cl-HAcAm when AOM was selected as the probe, and this process is facilitated by a long disinfection time.

\subsection{Effect of chlorine dose on the formation concentration of Cl-HAcAm}

The effect of chlorine dose on the formation of Cl-HAcAm was also investigated. In China, it is required that residual chlorine

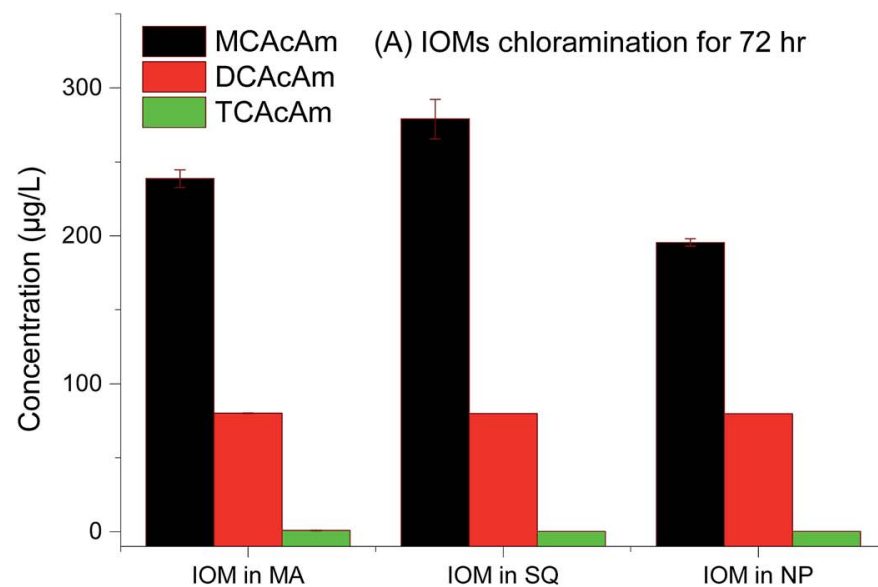

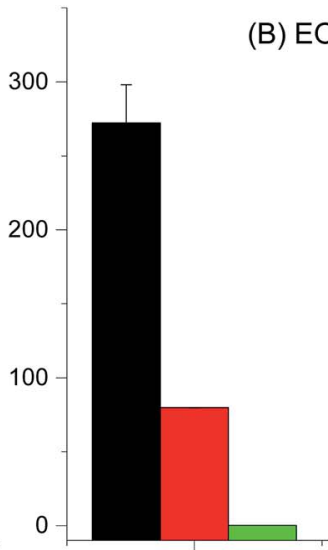

EOM in MA

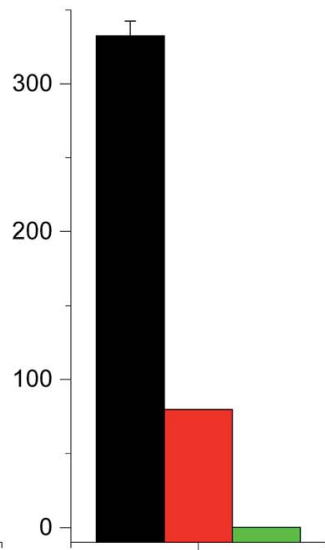

EOM in MA
(B) EOMs chloramination for $72 \mathrm{hr}$

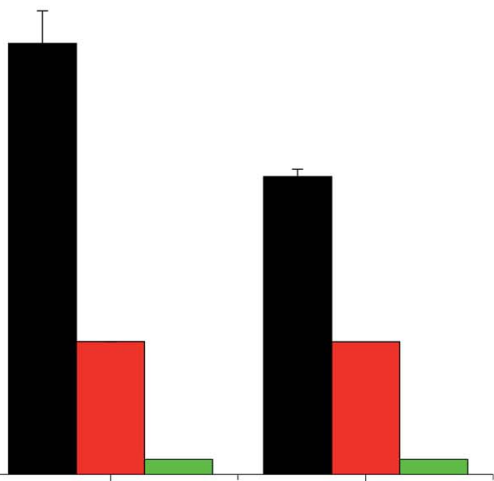

$E O M$ in $S Q$

$\mathrm{EOM}$ in NP

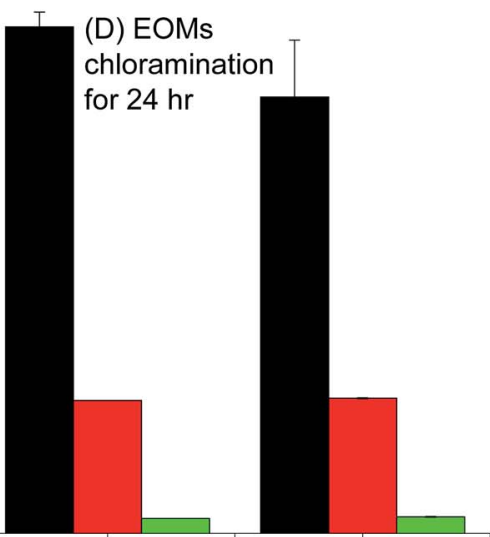

$E O M$ in $S Q$

EOM in NP

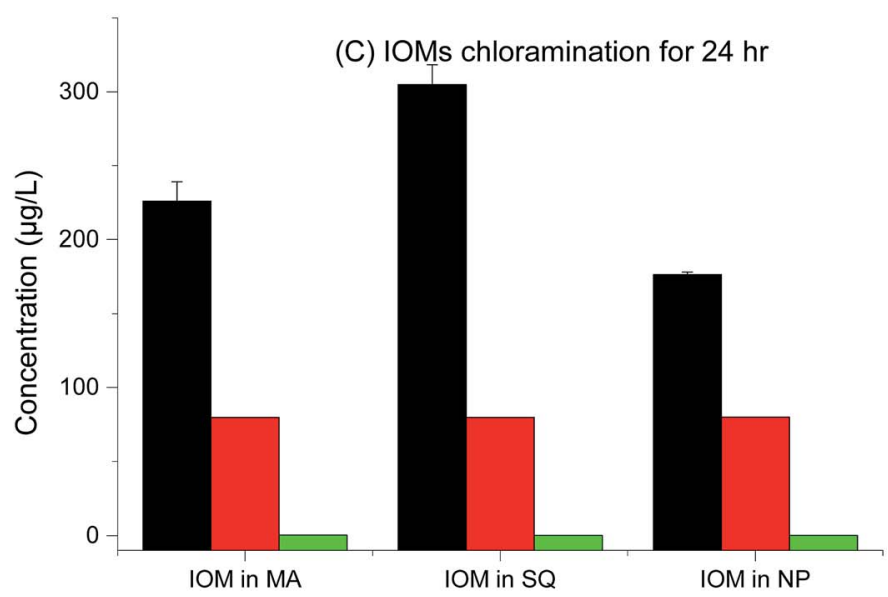

Fig. $3 \mathrm{Cl}$-HAcAm formation in chloramination AOMs extracted from different algae. 
must be higher than $0.05 \mathrm{mg} \mathrm{L}^{-1}$; therefore, after the disinfection process, the residual chlorine in each experiment was higher than $0.05 \mathrm{mg} \mathrm{L}^{-1}$. As shown in Fig. 4, the active chlorine dose had a significant effect on the formation of MCAcAm and TCAcAm in chlorination. When [active chlorine] was $2 \mathrm{mg} \mathrm{L}^{-1}$, the source of AOMs had a slight effect on the formation concentration of Cl-HAcAm, and MCAcAm was still the dominant Cl-HAcAm DBP. Excess [active chlorine] could lead to all precursors being transferred to Cl-HAcAm, but might oxidize the formed Cl-HAcAm to a certain degree. As [active chlorine] increased from $2 \mathrm{mg} \mathrm{L}^{-1}$ to $6 \mathrm{mg} \mathrm{L}^{-1}$, the concentration of MCAcAm formed increased and the final concentration was dependent on the algal species. This increasing effect was more significant for the sources of EOMs of MA (from 163.58 to $409.48 \mu \mathrm{g} \mathrm{L}^{-1}$ ) and SQ (from 163.45 to $391.93 \mu \mathrm{g} \mathrm{L}^{-1}$ ). The EOM property of MA and SQ was more positive for the formation of MCAcAm in chlorination, which was more significant when higher active chlorine doses were used. Almost no variation of DCAcAm formation concentration was observed in this study, as [active chlorine] increased. These results have not been reported when other precursors were used. Even though the formation yield of TCAcAm was very low, the variation of [active chlorine] influenced the formation of TCAcAm (Fig. 4) the toxicity of that was much higher than that of MCAcAm and DCAcAm. ${ }^{33}$ When EOM of NP was selected as the DBPs source, the formed TCAcAm increased from 0.22 to $1.09 \mu \mathrm{g} \mathrm{L}^{-1}$ with the corresponding dose of disinfectant. The composition of EOM produced by NP led to greater formation of TCAcAm than other AOM sources. Conversely, increasing [active chlorine] decreased TCAcAm yields when we used AOM from MA and SQ, suggesting that high levels of active chlorine degraded the generated
TCAcAm. The EOM of NP contained more precursor of TCAcAm, which was not observed in AOM from MA and SQ.

When switching the disinfectant to chloramine (Fig. 5), the effect of active chlorine dose on the formation concentration of Cl-HAcAm was similar to that in chlorination. The dominant ClHAcAm was still MCAcAm, and the increasing [active chlorine] led to increasing formation of MCAcAm in chloramination. The EOM of MA and SQ contributed more degree of the increasing concentration of MCAcAm, increasing nearly one times. Compared with chlorination, the EOM of NP contributed more yield of MCAcAm (from 163.47 to 285.07 $\mu \mathrm{g} \mathrm{L}^{-1}$ ) when the dose of chloramine increased. The increase in formation yield was greater for TCAcAm (from 0.07 to $1.21 \mu \mathrm{g} \mathrm{L}^{-1}$ ). Chloramination can form higher yield DBPs from AOM extracted from NP. Overall, a higher dose of disinfectant would promote the composites in EOM of MA and SQ to form MCAcAm, suggesting that the EOM of MA and SQ contained more precursors. These results were also observed for TCAcAm when the EOM of NP was used as a precursor. However, the precursor of TCAcAm in EOM of MA and SQ was limited, and a higher dose of active chlorine would degrade the formed TCAcAM.

\subsection{Effect of bromide on the formation concentration of Cl- HAcAm}

Bromide concentrations in drinking water resources of China can vary from a few micrograms per liter $\left(\mu \mathrm{g} \mathrm{\textrm {L } ^ { - 1 }}\right)$ to as much as several milligrams per liter $\left(\mathrm{mg} \mathrm{L}^{-1}\right)$. Bromide concentrations in water sources near coastal regions can be impacted by natural processes such as salt water intrusion, as well as by unique geological circumstances. ${ }^{36}$ Bromide can be oxidized to form

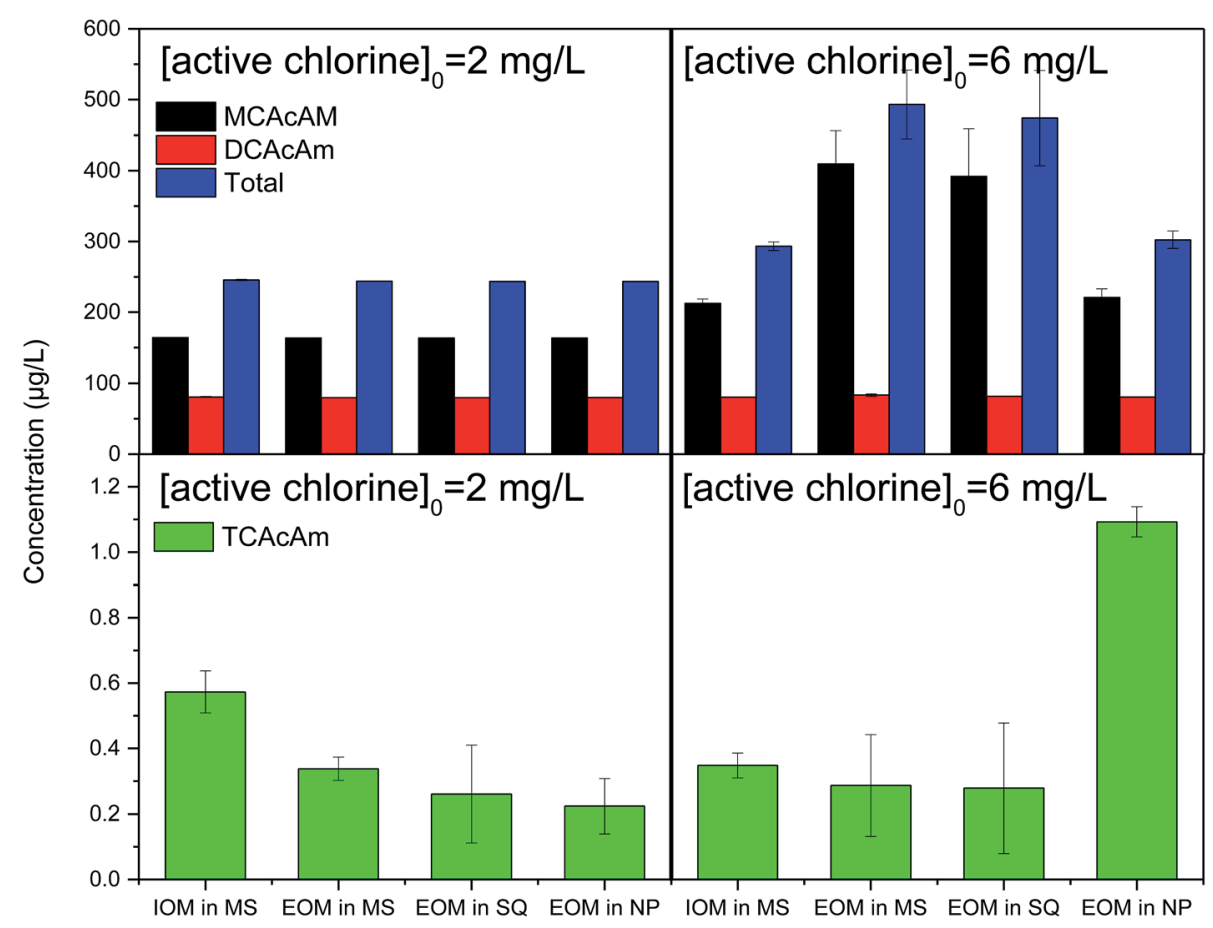

Fig. 4 Effect of active chlorine dose on $\mathrm{Cl}-\mathrm{HAcAm}$ formation in chlorination. 


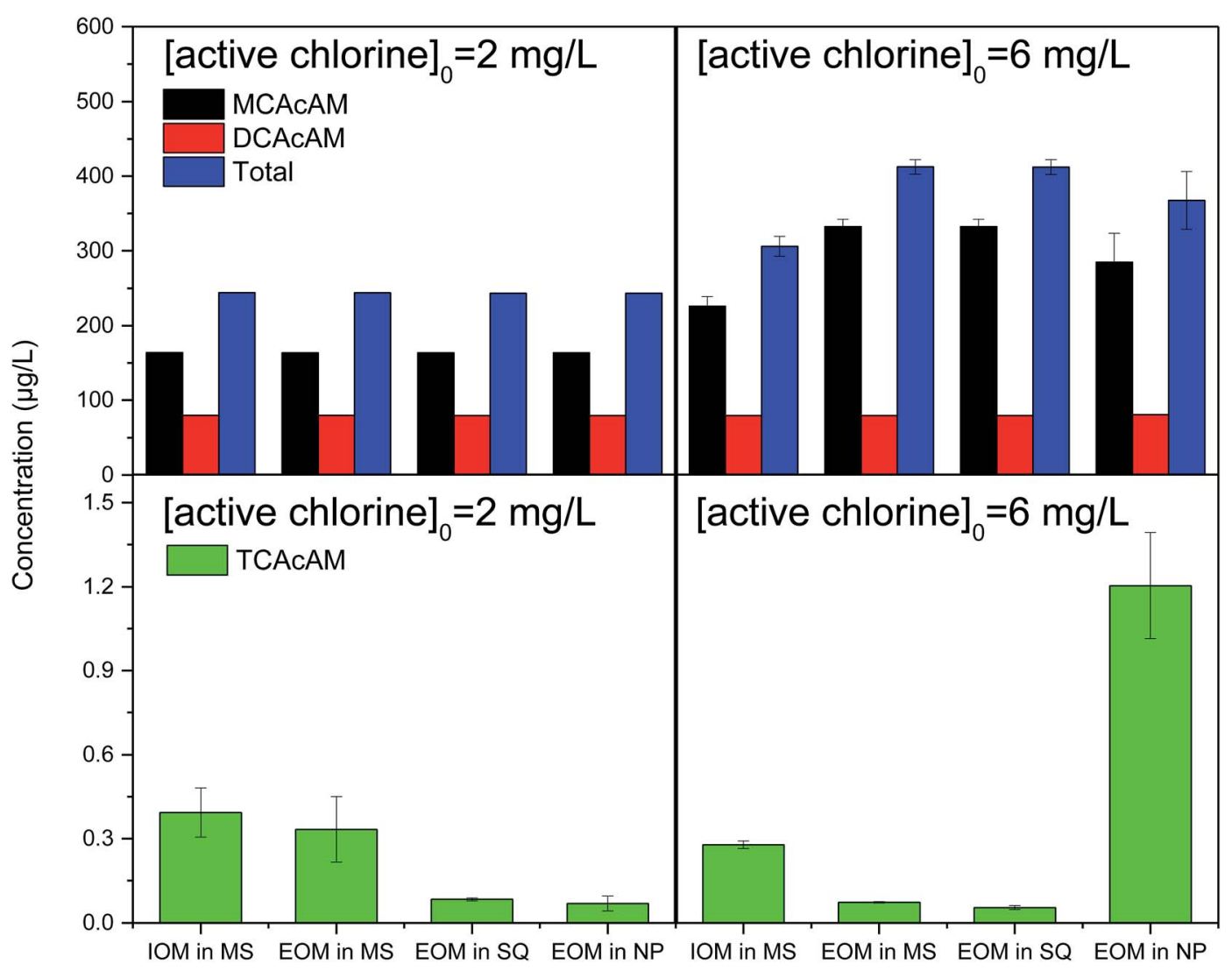

Fig. 5 Effect of active chlorine dose on $\mathrm{Cl}$-HAcAm formation in chloramination.

bromine $\left(\mathrm{HOBr}\right.$ or $\left.\mathrm{OBr}^{-}\right)$by chlorine $\left(\mathrm{HOCl}\right.$ or $\left.\mathrm{OCl}^{-}\right)$, reacting with NOM or AOM by either electrophilic substitution or addition to form the brominated organic by-products. ${ }^{37}$ In addition, the bromide in the brominated organic by-products is also oxidized to bromine for further reaction when chlorine is in excess. $^{38}$ The dissolved bromide also acted as a catalyst promoting the formation of NDMA. ${ }^{39}$ The effect of bromide on the formation of regular carbonaceous or nitrogenous DBPs from NOM has been thoroughly investigated..$^{40}$ The influence of bromide on the formation of Cl-HAcAm from AOMs observed in the present study is shown in Fig. 6 . It should be noted that brominated chloroacetamides (Br-HAcAm) were not studied because they are difficult to acquire in China and the actual concentration of bromide ion in freshwater is much lower. The presence of $\mathrm{Br}^{-}$decreased the formation concentration of MCAcAm generated from fractions of MA during both chlorination and chloramination. The decrease (from 488.89 to $212.77 \mu \mathrm{g} \mathrm{L}^{-1}$ ) of the formation concentration was greater when EOM of MA was used as the precursor during chlorination, compared with the disinfection process without bromine. The competition between bromine and chlorine led to bromine incorporation into the structure of organic compounds to form Br-HAcAm, ${ }^{41}$ which resulted in decreasing Cl-HAcAm formation. When the precursor was switched to AOM of SQ, the effect of $\mathrm{Br}^{-}$on the formation of Cl-AcAm was very small. These findings indicated that (1) $\mathrm{Br}^{-}$was more easily incorporated into the structure of AOM of MA to form Br-HAcAm, which was

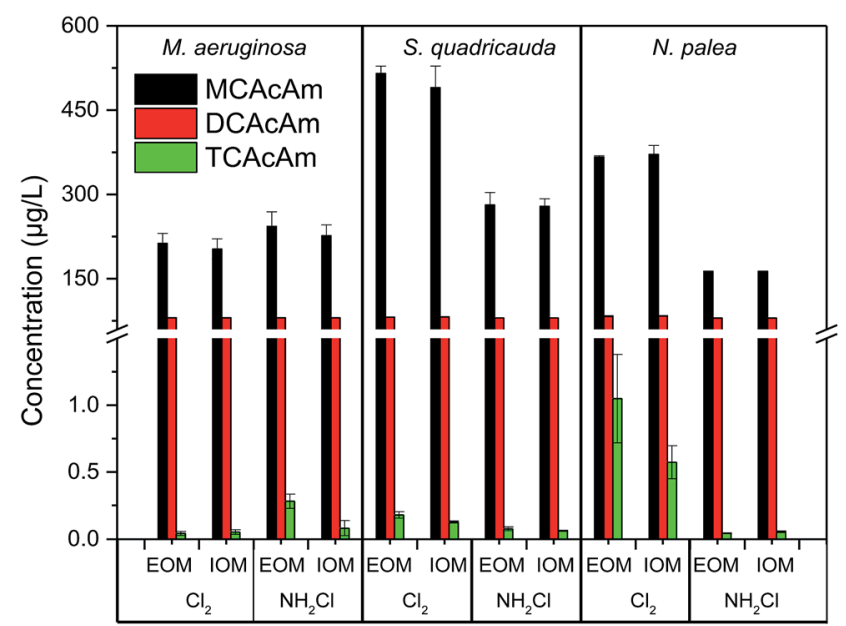

Fig. 6 Effect of $\mathrm{Br}^{-}$on $\mathrm{Cl}-\mathrm{HAcAm}$ formation in chlorination or chloramination.

not observed for SQ and NP AOM fractions; and (2) the significant decrease in the formation of Cl-HAcAm induced by bromide would lead to a higher yield of Br-HAcAm, resulting in a potential health risk. In the presence of $\mathrm{Br}^{-}$, chloramination is an option to decrease the formation concentration of HAcAm generated from AOM because the decreasing Cl-HAcAm (in total concentration) was very slight, especially for MA. When EOM/ IOM of MA was used as the precursor, the total concentration 
of Cl-HAcAm decreased by 28.42/12.83 $\mu \mathrm{g} \mathrm{L}^{-1}$ or $276.76 / 36.55$ $\mu \mathrm{g} \mathrm{L}^{-1}$ in response to chloramination or chlorination.

\section{Conclusion}

Based on the above discussion, it was concluded that

(1) With the exception of Microcystis aeruginosa, other algal species formed greater amounts of AOM, which might influence the water quality and performance of drinking water treatment. Diatoms and green algae should receive greater consideration in limnological studies related to NOMs and drinking water treatment.

(2) Different from previous studies, AOM made a significant contribution to MCAcAm formation during the disinfection process, with Scenedesmus quadricauda and Nitzschia palea having a more remarkable influence on MCAcAm formation. Chlorination showed higher yields of Cl-HAcAm than chloramination, and the nitrogen in Cl-HAcAm came from the structure of AOM.

\section{Abbreviations}

$\begin{array}{ll}\text { MA } & \text { Microcystis aeruginosa } \\ \text { SQ } & \text { Scenedesmus quadricauda } \\ \text { NP } & \text { Nitzschia palea } \\ \text { DBPs } & \text { Disinfection byproducts } \\ \text { AOM } & \text { Algal organic matter } \\ \text { EOM } & \text { Extracellular organic matter } \\ \text { IOM } & \text { Intracellular organic matter } \\ \text { HAcAms } & \text { Haloacetamides } \\ \text { MCAcAm } & \text { Monochloroacetamide } \\ \text { DCAcAm } & \text { Dichloroacetamide } \\ \text { TCAcAm } & \text { Trichloroacetamide } \\ \text { BAcAm } & \text { Bromoacetamide } \\ \text { DBAcAm } & \text { Dibromoacetamide } \\ \text { DOC } & \text { Dissolved organic carbon } \\ \text { BSA } & \text { Bovine serum albumin } \\ \text { GC-ECD } & \text { Gas chromatograph electron capture detector }\end{array}$

\section{Acknowledgements}

This work was carried out with the support of Fundamental Research Funds for the Central Universities (No. 2015ZCQ-HJ02), the National Natural Science Foundation of China (No. 51578520, 51378063, 41273137 and 51108030) and Beijing Natural Science Foundation (No. L160006).

\section{References}

1 M. Yang, J. Yu, Z. Li, Z. Guo, M. Burch and T.-F. Lin, Science, 2008, 319, 158.

2 P. Xie, J. Ma, J. Fang, Y. Guan, S. Yue, X. Li and L. Chen, Environ. Sci. Technol., 2013, 47, 14051-14061.

3 J. Fang, X. Yang, J. Ma, C. Shang and Q. Zhao, Water Res., 2010, 44, 5897-5906.
4 J. D. Plummer and J. K. Edzwald, Environ. Sci. Technol., 2001, 35, 3661-3668.

5 S. Zhou, Y. Shao, N. Gao, Y. Deng, L. Li, J. Deng and C. Tan, Water Res., 2014, 52, 199-207.

6 X. Yang, W. Guo and W. Lee, Chemosphere, 2013, 91, 14771485.

7 W. Chu, N. Gao, D. Yin and S. W. Krasner, J. Hazard. Mater., 2013, 260, 806-812.

8 S. W. Krasner, H. S. Weinberg, S. D. Richardson, S. J. Pastor, R. Chinn, M. J. Sclimenti, G. D. Onstad and A. D. Thruston, Environ. Sci. Technol., 2006, 40, 7175-7185.

9 F. Yang, J. Zhang, W. Chu, D. Yin and M. R. Templeton, J. Hazard. Mater., 2014, 274, 156-163.

10 M. Leloup, R. Nicolau, V. Pallier, C. Yéprémian and G. Feuillade-Cathalifaud, J. Environ. Sci., 2013, 25, 10891097.

11 M. Zhu, N. Gao, W. Chu, S. Zhou, Z. Zhang, Y. Xu and Q. Dai, Ecotoxicol. Environ. Saf., 2015, 120, 256-262.

12 J. C. Servaites, J. L. Faeth and S. S. Sidhu, Anal. Biochem., 2012, 421, 75-80.

13 A. Laurentin and C. A. Edwards, Anal. Biochem., 2003, 315, 143-145.

14 S. Chutipongtanate, K. Watcharatanyatip, T. Homvises, K. Jaturongkakul and V. Thongboonkerd, Talanta, 2012, 98, 123-129.

15 A. Dotson, P. Westerhoff and S. W. Krasner, Water Sci. Technol., 2009, 60, 135-143.

16 W.-H. Chu, N.-Y. Gao, Y. Deng and S. W. Krasner, Environ. Sci. Technol., 2010, 44, 3908-3912.

17 C. M. M. Bougeard, E. H. Goslan, B. Jefferson and S. A. Parsons, Water Res., 2010, 44, 729-740.

18 K. Doederer, M. J. Farré, M. Pidou, H. S. Weinberg and W. Gernjak, J. Membr. Sci., 2014, 467, 195-205.

19 W. Chu, X. Li, T. Bond, N. Gao, X. Bin, Q. Wang and S. Ding, Water Res., 2016, 107, 141-150.

20 T.-L. Chen, S.-H. Tzing and W.-H. Ding, J. Chromatogr. A, 2015, 1422, 340-344.

21 S. Y. Kimura, Y. Komaki, M. J. Plewa and B. J. Mariñas, Environ. Sci. Technol., 2013, 47, 12382-12390.

22 Q. Yang, P. Xie, H. Shen, J. Xu, P. Wang and B. Zhang, Water Res., 2012, 46, 2525-2534.

23 R. K. Henderson, A. Baker, S. A. Parsons and B. Jefferson, Water Res., 2008, 42, 3435-3445.

24 X. Yang, W. Guo and Q. Shen, J. Hazard. Mater., 2011, 197, 378-388.

25 H. Chu, H. Yu, X. Tan, Y. Zhang, X. Zhou, L. Yang and D. Li, Colloids Surf., B, 2015, 125, 238-246.

26 W. Chu, X. Li, N. Gao, Y. Deng, D. Yin, D. Li and T. Chu, Sci. Rep., 2015, 5, 14412.

27 L. Li, N. Gao, Y. Deng, J. Yao and K. Zhang, Water Res., 2012, 46, 1233-1240.

28 H.-K. Park, Y.-C. Seo, I.-H. Cho and B.-H. Park, J. Korean Soc. Water Environ., 2006, 22, 513-520.

29 J. D. Plummer and J. K. Edzwald, Environ. Sci. Technol., 2001, 35, 3661-3668.

30 W. Chu, D. Li, N. Gao, D. Yin, Y. Zhang and Y. Zhu, Chem. Eng. J., 2015, 281, 623-631. 
31 W.-h. Chu, N.-y. Gao and Y. Deng, J. Hazard. Mater., 2010, 173, 82-86.

32 W. Chu, N. Gao and Y. Deng, Chin. J. Org. Chem., 2009, 29, 6.

33 M. J. Plewa, M. G. Muellner, S. D. Richardson, F. Fasano, K. M. Buettner, Y.-T. Woo, A. B. McKague and E. D. Wagner, Environ. Sci. Technol., 2008, 42, 955-961.

34 D. Liew, K. L. Linge, C. A. Joll, A. Heitz and J. W. A. Charrois, J. Chromatogr. A, 2012, 1241, 117-122.

35 X. Liao, J. Liu, M. Yang, H. Ma, B. Yuan and C.-H. Huang, Sci. Total Environ., 2015, 532, 540-547.

36 J. Tan, S. Allard, Y. Gruchlik, S. McDonald, C. A. Joll and A. Heitz, Sci. Total Environ., 2016, 541, 1572-1580.
37 J. Criquet, E. M. Rodriguez, S. Allard, S. Wellauer, E. Salhi, C. A. Joll and U. von Gunten, Water Res., 2015, 85, 476486.

38 P. Westerhoff, P. Chao and H. Mash, Water Res., 2004, 38, 1502-1513.

39 L. Yang, Z. Chen, J. Shen, Z. Xu, H. Liang, J. Tian, Y. Ben, X. Zhai, W. Shi and G. Li, Environ. Sci. Technol., 2009, 43, 5481-5487.

40 M. B. Heeb, J. Criquet, S. G. Zimmermann-Steffens and U. von Gunten, Water Res., 2014, 48, 15-42.

41 M. Yang and X. Zhang, Environ. Sci. Technol., 2013, 47, 10868-10876. 